\title{
After Action Report: Central Facilities Area 2014 Evaluated Drill September 30, 2014
}

November 2014

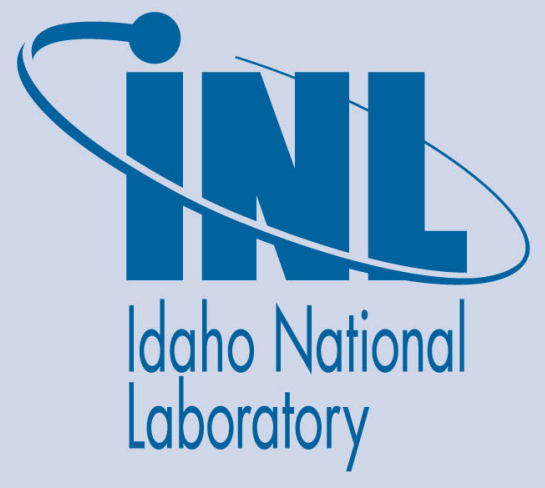

The INL is a U.S. Department of Energy National Laboratory operated by Battelle Energy Alliance 


\section{DISCLAIMER}

This information was prepared as an account of work sponsored by an agency of the U.S. Government. Neither the U.S. Government nor any agency thereof, nor any of their employees, makes any warranty, expressed or implied, or assumes any legal liability or responsibility for the accuracy, completeness, or usefulness, of any information, apparatus, product, or process disclosed, or represents that its use would not infringe privately owned rights. References herein to any specific commercial product, process, or service by trade name, trade mark, manufacturer, or otherwise, does not necessarily constitute or imply its endorsement, recommendation, or favoring by the U.S. Government or any agency thereof. The views and opinions of authors expressed herein do not necessarily state or reflect those of the U.S. Government or any agency thereof. 
INL/EXT-14-33491

Revision 0

\section{After Action Report: Central Facilities Area 2014 Evaluated Drill September 30, 2014}

November 2014

Idaho National Laboratory Idaho Falls, Idaho 83415

http://www.inl.gov

\section{Prepared for the}

U.S. Department of Energy

Under DOE Idaho Operations Office

Contract DE-AC07-05ID14517 
This page intentionally left blank. 


\section{Emergency Management}

\section{After Action Report: Central Facilities Area 2014 Evaluated Drill September 30, 2014}

INL/EXT-14-33491

Revision 0

November 2014

Submitted by Scott Barnes

Date

Drill Director

Approved by Carl Farmer

Date

INL Emergency Management Manager 
This page intentionally left blank. 


\section{CONTENTS}

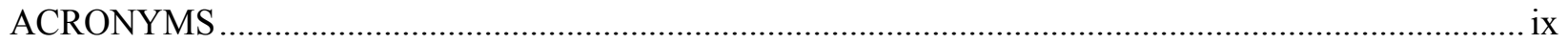

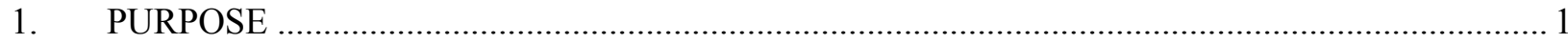

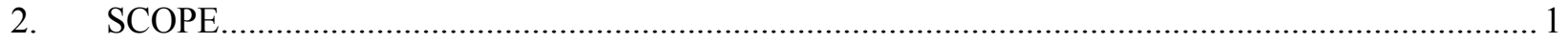

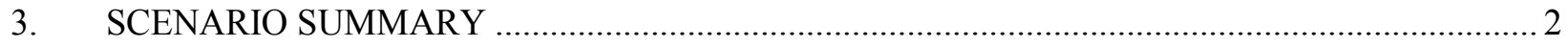

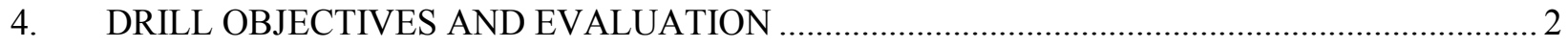

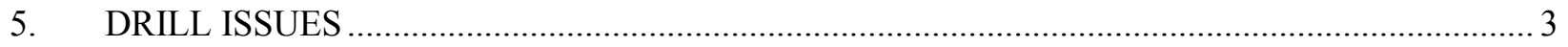

5.1 Emergency Response Organization Response ........................................................... 3

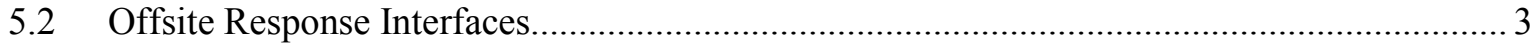

5.3 Emergency Event Categorization and Classification ................................................... 4

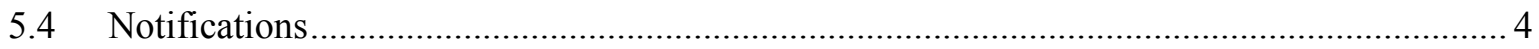

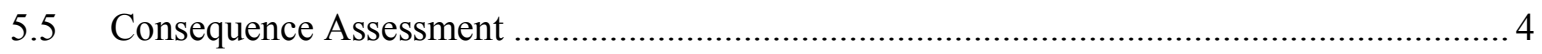

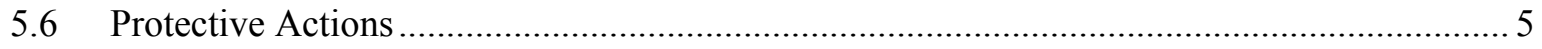

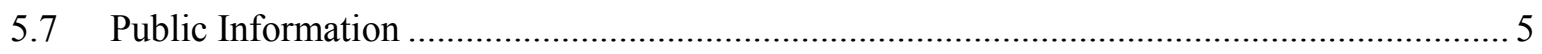

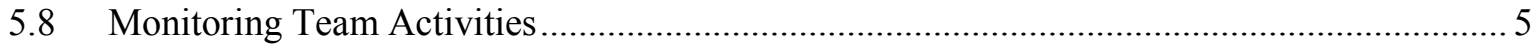

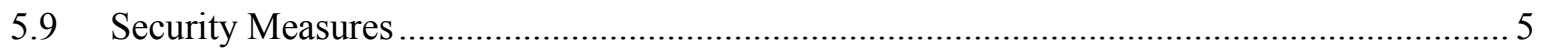

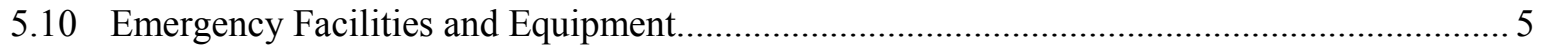

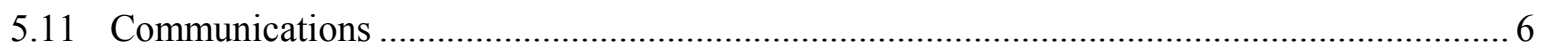

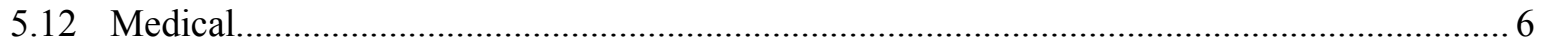

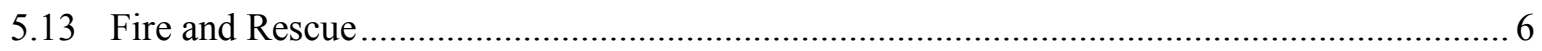

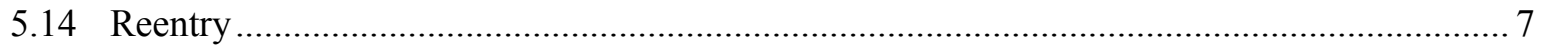

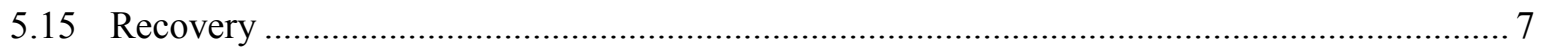

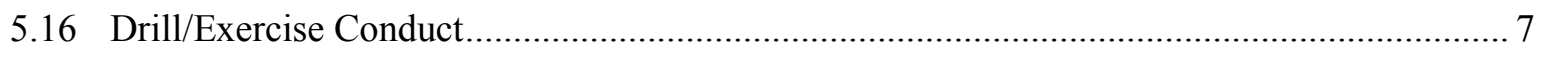

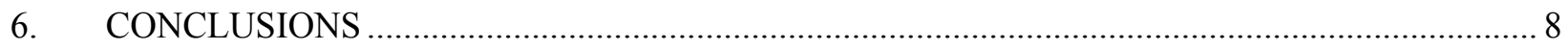

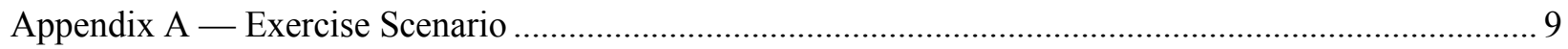

TABLES

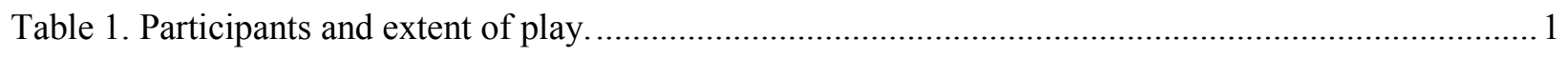

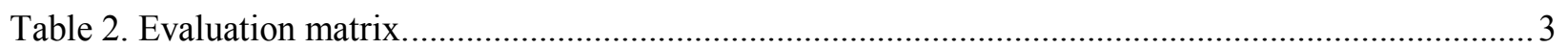


This page intentionally left blank. 


\section{ACRONYMS}

BEA Battelle Energy Alliance LLC

CFA Central Facilities Area

EAM emergency action manager

ECC emergency control center

ED emergency director

EOC Emergency Operations Center

ERO emergency response organization

IC incident commander

INL Idaho National Laboratory

JIC Joint Information Center

OE operational emergency

WCC Warning Communications Center 
This page intentionally left blank. 


\section{After Action Report: Central Facilities Area 2014 Evaluated Drill September 30, 2014}

\section{PURPOSE}

On September 30, 2014, Central Facilities Area (CFA), operated by Battelle Energy Alliance, LLC, at Idaho National Laboratory (INL), conducted an evaluated emergency drill to allow the CFA Emergency Response Organization (ERO) to demonstrate their ability to respond to and mitigate an emergency event.

\section{SCOPE}

Participants and their extent of play are shown in Table 1.

Table 1. Participants and extent of play.

\begin{tabular}{|c|c|}
\hline Participants & Extent of Play \\
\hline \multicolumn{2}{|c|}{ INL Organizations } \\
\hline CFA Emergency Control Center (ECC) & Full participation \\
\hline INL Bus Operations & Simulated (if requested) \\
\hline INL Emergency Operations Center (EOC) & Limited participation: Control cell \\
\hline INL Fire Alarm Center & Limited participation: Notifications only \\
\hline INL Fire Department & Limited participation: Control cell \\
\hline INL Joint Information Center (JIC) & Limited participation: Control cell \\
\hline INL Occupational Medicine & Limited participation: Notifications only \\
\hline INL Security & Limited participation: Control cell \\
\hline INL Site Monitoring Team & Simulated (if requested) \\
\hline INL Warning Communications Center (WCC) & Full participation \\
\hline \multicolumn{2}{|c|}{ Contiguous Counties } \\
\hline Bingham & Limited: Notifications only \\
\hline Bonneville & Limited: Notifications only \\
\hline Butte & Limited: Notifications only \\
\hline Clark & Limited: Notifications only \\
\hline Jefferson & Limited: Notifications only \\
\hline \multicolumn{2}{|c|}{ State of Idaho Agencies } \\
\hline Idaho Radiation Control Program & Limited: Communications only \\
\hline Idaho State Communications Center & Limited: Notifications and communications \\
\hline Idaho State Police & Limited: Notifications only \\
\hline INL Oversight Program & Limited: Notifications only \\
\hline \multicolumn{2}{|c|}{ Tribal Authority } \\
\hline Shoshone/Bannock Tribe & Limited: Notifications only \\
\hline
\end{tabular}




\section{SCENARIO SUMMARY}

\section{Background}

CFA is the main service and support center for the programs located at primary INL Site facility areas. A major portion of the activity at CFA consists of INL sitewide programmatic support such as transportation, maintenance, capital construction, environmental and radiological monitoring, security, fire protection, warehouses, calibration laboratories, and a cafeteria. A small amount of research and development work is also conducted at CFA. Work on radioactive and hazardous material is restricted in and around CFA.

\section{$\underline{\text { Start }}$}

It was a normal working day at CFA. A mechanic at CFA-696, CFA Transportation Complex, had been assigned to repair the pump on tanker truck No. 71601, which is a gasoline tanker used to occasionally supply gasoline to the various fueling stations at the Site. The mechanic pulled the truck into CFA-696 on the heavy-equipment-side bay No. 23. The mechanic exited the truck and chocked the tires. Using a normal drop light, the mechanic began work by turning the isolation valve to the pump, located under the truck, to the off position. Unknown to the mechanic, the valve malfunctioned and did not completely shut off. The mechanic proceeded to disconnect the pump coupler. The coupler broke, spilling a large quantity of gasoline on the mechanic's clothes and the floor. The mechanic dropped the light and tried to retreat. The light struck the floor and ignited the gasoline on both the mechanic's clothes and the floor.

A nearby mechanic saw what happened, pulled the manual fire alarm, and ran to help extinguish the fire on the other mechanic's clothes. The gasoline continued to burn as it drained from the truck. The gasoline spread across the floor and made contact with a service truck parked in bay No. 22. The service truck began to burn.

The INL Fire Department was dispatched to the scene and the INL WCC notified the CFA emergency action manager (EAM) and INL EOC support director. The CFA EAM directed the INL WCC to activate the CFA ECC and then proceeded to the ECC. The INL WCC established a conference call with the INL EOC support director and INL emergency director (ED). The INL ED requested activation of the INL EOC and INL JIC (simulated by control cell).

\section{DRILL OBJECTIVES AND EVALUATION}

NOTE: Only the CFA ERO was formally evaluated during the drill. All other player organizations were conducting a training evolution.

During the drill, 10 of the 16 standardized INL objectives were evaluated for CFA using the appropriate demonstration criteria. Eight objectives were rated satisfactory and two objectives were rated satisfactory with improvement needed.

The ratings in Table 2 are based on the issues that follow in Section 5 of this report. 
Table 2. Evaluation matrix.

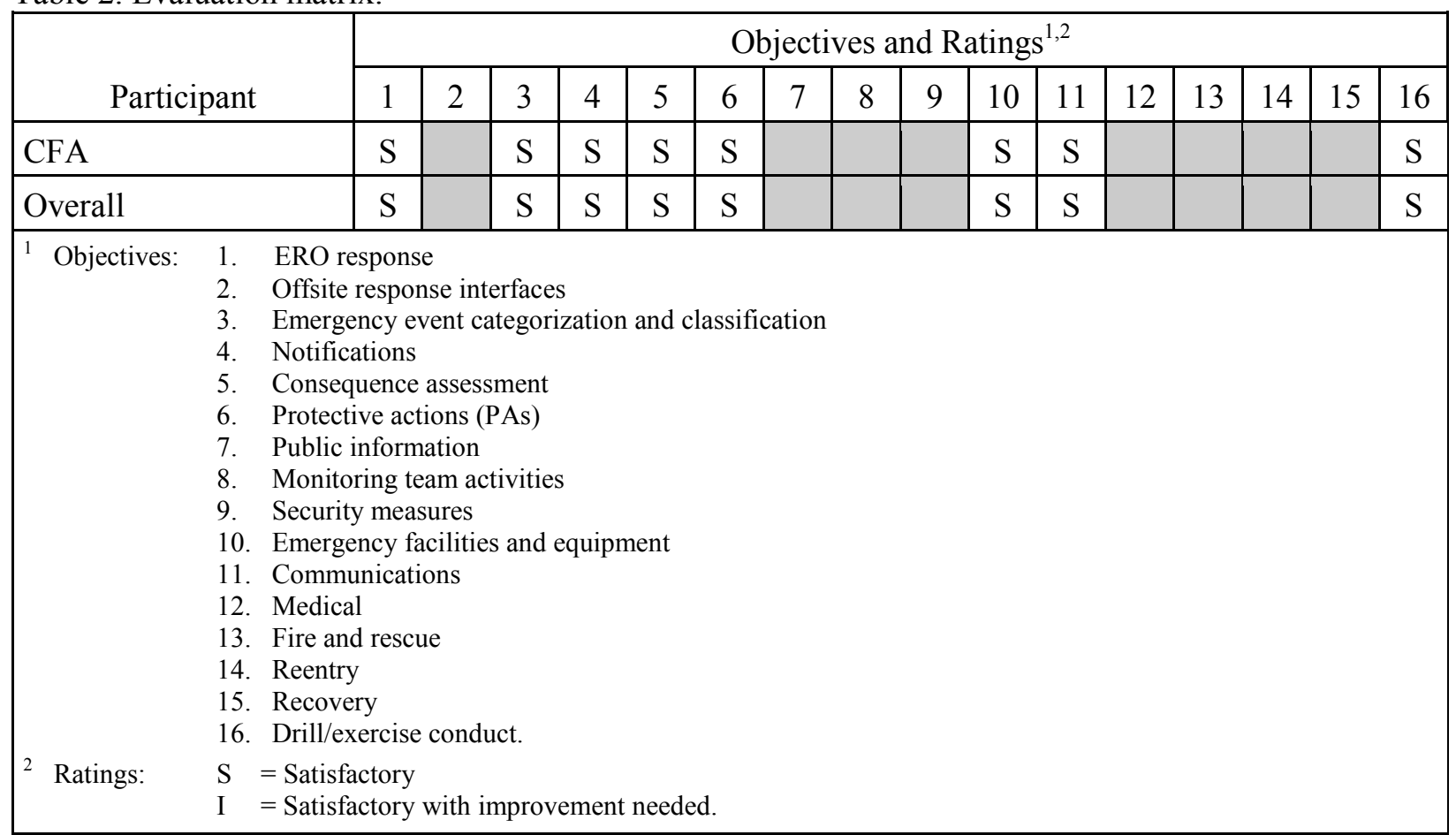

\section{DRILL ISSUES}

The following issues are specific to the evaluation of CFA. Each item has been evaluated and entered into the appropriate issues management system.

\subsection{Emergency Response Organization Response}

Given the facility procedures/plan, the ERO will respond to, monitor, and evaluate the specific indicators of an emergency for mitigation of the consequences and bring the emergency situation under control.

\section{$\underline{\text { Discussion }}$}

The CFA EAM requested the INL WCC to activate the on-duty CFA ERO team. The INL EOC and INL JIC were activated as control cells. The INL WCC activated the on-duty CFA ERO team.

The CFA EAM demonstrated excellent command and control of the event throughout the drill, was knowledgeable of the CFA ERO mission, and was actively concerned with the safety of all personnel.

\section{Issues}

No issues were identified.

\subsection{Offsite Response Interfaces}

Given the facility procedures/plan, the ERO will coordinate and interface with response organizations to protect the environment and health and safety of the public.

\section{Issues}

- Not evaluated. 


\subsection{Emergency Event Categorization and Classification}

Given the facility procedures/plan, the ERO will accurately and promptly categorize and classify the operational emergency $(\mathrm{OE})$.

\section{Discussion}

Using input provided by other CFA ERO team members, the CFA EAM recognized and categorized the event as an unclassified OE using the appropriate emergency action level. Event categorization occurred within the required 15 minutes of event determination. After receiving information from the INL Fire Department incident commander (IC), a good discussion occurred among CFA ECC decision-makers. A successful transfer of the categorization and classification function between the CFA EAM and the INL ED occurred with documentation of the significant event. When event conditions changed, the CFA EAM provided the INL ED in the INL EOC with the applicable information.

\section{Issues}

- No issues were identified.

\subsection{Notifications}

Given the facility procedures/plan, the ERO will report emergencies and conduct follow-up notifications to the appropriate organizations within the required time.

\section{Discussion}

The CFA ECC support manager coordinated information with the CFA EAM and accurately completed and faxed the notification form to the INL WCC. The INL WCC established communications with offsite agencies and provided the information to the participating agencies. The CFA ECC support manager asked the INL WCC operator to be included in the offsite notification process. However, when the INL WCC tried to establish communication with the CFA ECC support manager the phone line was busy. In order to complete the notification process within the required time limit, the INL WCC completed offsite notifications without inclusion of the CFA ECC support manager in the call. The initial offsite notification was completed within the 30-minute notification time requirement for an unclassified OE. Notification responsibilities were successfully transferred from the CFA EAM to the INL ED per the applicable procedure. All follow-up notifications were simulated.

\subsection{Consequence Assessment}

Given the facility procedures/plan, the ERO will assess actual and potential onsite and offsite consequences of an emergency.

\section{Discussion}

Ongoing consequence assessment was successfully conducted with the CFA ECC planning manager monitoring the event, assessing potential consequences, and correctly completing and submitting the consequence assessment form to the INL EOC control cell for concurrence. 


\subsection{Protective Actions}

Given the facility procedures/plan, the ERO will respond to emergency conditions to protect onsite personnel and the public by implementing specific, predetermined actions.

\section{Discussion}

The INL Fire Department IC requested that CFA be placed in a take shelter PA for crowd control, which was simulated as occurring, about the same time that the CFA EAM arrived at the CFA ECC. Though the major part of CFA was upwind of the fire at the time the IC requested the PA, the CFA EAM supported the PA throughout the drill. The CFA EAM and support staff continued to monitor conditions throughout the event and verified the PAs were adequate for the hazards present. PAs and PA recommendations were successfully transferred by the CFA EAM to the INL ED.

\subsection{Public Information}

Given the facility procedures/plan, the ERO will demonstrate an emergency public information program.

$\underline{\text { Issues }}$

- Not evaluated.

\subsection{Monitoring Team Activities}

Given the facility procedures/plan, the ERO will provide facility/site monitoring teams in support of consequence assessment activities.

\section{$\underline{\text { Issues }}$}

- Not evaluated.

\subsection{Security Measures}

Given the facility procedures/plan, Security will respond to, monitor, and evaluate the specific indicators of an emergency for mitigation of the consequences and bring the emergency situation under control.

Issues

- Not evaluated.

\subsection{Emergency Facilities and Equipment}

Demonstrate the adequacy of facilities, equipment, displays, and other materials to support emergency operations.

\section{Discussion}

The CFA ECC planning manager attempted to fax the consequence assessment form to the INL EOC. However, the CFA ECC planning manager was unaware of a problem with the fax machine, which required entering the prefix 9 prior to the fax number. This caused a delay in the form getting to the INL EOC planning director. The CFA ECC planning manager requested assistance from the CFA ECC support manager and the issue was resolved and the form faxed to the INL EOC.

All other CFA facilities and equipment functioned properly and were adequate to support emergency response. The smart board was utilized to display iMap to identify the location of the event, hazards, and response personnel. 
$\underline{\text { Issues }}$

- This is a recurring problem with this fax machine.

Recommendation: Interim: The CFA emergency planner will place a card at the fax machine stating the proper format to enter a fax number. The CFA emergency planner will also send a note to all CFA ERO members stating the proper operation of the fax machine. Long Term: The CFA emergency planner will evaluate the equipment to determine if the issue is with the fax machine or phone line. Laboratory Protection LabWay No. LP-CO-2014-0694 assigned.

\subsection{Communications}

Communications capabilities are managed in support of emergency operations to ensure prompt and appropriate flow of accurate information during an emergency.

\section{$\underline{\text { Discussion }}$}

Communications demonstrated within the CFA ECC and between the CFA ECC and INL EOC were effective. The communications system used during this drill worked effectively. This included phones, radios, computers, and WebEOC. CFA ERO members effectively used repeatbacks in their communications.

\section{Issues}

- It was noted in the after action review that there was a limited amount of significant event entries documented in the WebEOC system.

Recommendation: The CFA emergency planner will send a note to CFA ERO members reminding them to complete WebEOC significant event entries per EPI-82, "Emergency Information Management System.” Laboratory Protection LabWay No. LP-CO-2014-0695 assigned for tracking and trending.

\subsection{Medical}

Given the facility procedures/plan, medical response personnel will respond to, monitor, and evaluate the specific indicators of an emergency for mitigation of the consequences and bring the emergency situation under control.

Issues

- Not evaluated.

\subsection{Fire and Rescue}

Given the procedures/plan, fire and rescue responders will respond to an event involving fire or hazardous material, mitigate the consequences, and bring the situation under control.

\section{Issues}

- Not evaluated. 


\subsection{Reentry}

The ERO will demonstrate development and implementation of a reentry plan to include debriefing of the reentry team and proper recordkeeping in accordance with the facility procedures/plan.

\section{Discussion}

Although this objective was originally documented as one to be evaluated during the drill, the drill director determined to terminate the drill prior to objective demonstration. This decision was based on the length of time the drill had already taken and from listening to discussions on the progress of event mitigation. During these discussions, the CFA EAM and CFA ECC support staff discussed various potential tasks that could be done under a reentry plan but the CFA EAM made a comment that a reentry would not be made until after the INL Fire Department was done and had cleared the scene and that most likely these activities would be done in the recovery phase.

\section{Issues}

- No issues were identified.

\subsection{Recovery}

Given the facility procedures/plan, the ERO will demonstrate recovery planning for an emergency at the affected facility.

\section{Discussion}

Although this objective was originally documented as one to be evaluated during the drill, the drill director determined to terminate the drill prior to naming a recovery manager. This decision was based on the length of time the drill had already taken and from listening to discussions on the progress of event mitigation. During these discussions, the CFA EAM and CFA ECC support staff were well focused on event mitigation. Some discussion points identified specific tasks that would be completed during recovery operations and that they would not address them during the ongoing mitigation efforts. At no time was a recovery manager discussed.

Issues

- No issues were identified.

\subsection{Drill/Exercise Conduct}

Write, conduct, and evaluate a drill/exercise that will emphasize facility-specific emergency events and response activities and minimize the use of generic, nonspecific simulations in accordance with the facility procedures/plan.

\section{Discussion}

The drill scenario was realistic and provided a good opportunity for CFA ERO members to demonstrate their response capabilities. The Master Sequence of Events List provided for a controlled supply of activities in a timely manner that kept CFA ERO members involved and responding to information in a productive and effective manner. Controllers and evaluators were effectively used throughout the drill. Applicable critiques were held that allowed all personnel the opportunity to provide feedback.

\section{Issues}

- No issues were identified. 


\section{CONCLUSIONS}

A successful evaluated drill was conducted at CFA. Overall, 10 objectives were evaluated for response by the CFA ERO. Eight objectives were rated satisfactory and two objectives were rated satisfactory with improvement needed.

The CFA EAM rapidly activated the CFA ERO and declared the CFA ECC operational. Categorization of the event as an OE and PA determination and implementation were effective and done in a timely manner with priorities given to personnel safety. Offsite notifications were completed according to procedures and within time requirements. The CFA EAM demonstrated command and control by effectively making assignments and seeing that they were completed. The CFA EAM made periodic briefings to update CFA ERO members on the status of the event and allowed sufficient time for CFA ERO members to report any updated or new information. Emergency facilities and equipment were available and operated as designed. Communications were appropriately demonstrated within the CFA ECC and between the CFA ECC and INL EOC by effectively using repeatbacks to verify information and investigating unverified information for correctness. Controllers and evaluators were effectively used during this drill. The overall evaluation of this drill, including the performance of the players, controllers, and evaluators, was satisfactory. 


\section{Appendix A}

\section{Exercise Scenario}

\section{Background}

The Central Facilities Area (CFA) is the main service and support center for the programs located at primary Idaho National Laboratory (INL) Site facility areas. A major portion of the activity at CFA consists of INL sitewide programmatic support such as transportation, maintenance, capital construction, environmental and radiological monitoring, security, fire protection, warehouses, calibration laboratories, and a cafeteria. A small amount of research and development work is also conducted at CFA. Work on radioactive and hazardous material is restricted in and around CFA.

\section{$\underline{\text { Start }}$}

It is a normal working day at CFA. A mechanic at CFA-696, CFA Transportation Complex, is assigned to repair the pump on tanker truck No. 71601, which is a gasoline tanker used to occasionally supply gasoline to the various fueling stations at the Site. The mechanic pulls the truck into CFA-696 on the heavy-equipment-side bay No 23. The mechanic exits the truck and chocks the tires. Using a normal drop light, the mechanic begins work by turning the isolation valve to the pump, located under the truck, to the off position. Unknown to the mechanic, the valve malfunctions and does not shut off completely. The mechanic proceeds to disconnect the pump coupler. The coupler breaks, spilling a large quantity of gasoline onto the mechanic's clothes and the floor. The mechanic drops the light and tries to retreat. The light strikes the floor and ignites the gasoline on both the mechanic's clothes and the floor.

A nearby mechanic sees what happened, pulls the manual fire alarm, and runs to help extinguish the fire on the other mechanic's clothes. The gasoline continues to burn as it drains from the truck. The gasoline spreads across the floor and makes contact with a service truck parked in bay No. 22. The service truck begins to burn.

The INL Fire Department is dispatched to the scene and the INL Warning Communications Center (WCC) notifies the CFA emergency action manager (EAM) and INL Emergency Operations Center (EOC) support director. The CFA EAM directs the INL WCC to activate the CFA Emergency Control Center (ECC) and then proceeds to the CFA ECC. The INL WCC establishes a conference call with the INL EOC support director and INL emergency director. The INL emergency director requests activation of the INL EOC and INL Joint Information Center (simulated by control cell).

The INL Fire Department arrives on scene, sets up a command post on the south side of CFA-696, and begins scene size up. The gasoline continues to spread and burn inside CFA-696. CFA-696 has been evacuated and accountability is complete. The fire on the mechanic is extinguished. INL Fire Department personnel immediately begin medical treatment on the mechanic upon arrival at the scene. Heavy black smoke is coming from the heavy equipment side (eastside) of CFA-696. INL Fire Department access to CFA-696 is limited due to the smoke and structural concerns. The fire has spread from the service truck in bay No. 22 to the INL Fire Department hazardous material van in bay No. 21, which is in CFA-696 for service. The INL Fire Department attempts to access CFA-696 through doors on the south side of the building. The INL Fire Department reports that the service truck is loaded with the following types of flammable chemicals: engine coolant, hydraulic fluid, automatic transmission fluid, engine oil, 90-weight gear oil, waste oil mixture, and diesel fuel. There is also diesel fuel, hydraulic fluid, and up to 16 compressed air bottles in the hazardous material van.

The injured mechanic is en route to the CFA Medical Clinic with severe hand and leg burns. The INL Fire Department requests Air Idaho Rescue to transport the patient. 
The CFA EAM arrives at the CFA ECC and categorizes the event using emergency action level CFA-ALL-1.OE.1. Preparations begin for possible facility evacuation. The notification form is completed and faxed to the INL WCC. Offsite notifications are completed.

The fire grows in size and intensity. The INL Fire Department uses indirect suppression tactics. Indications of possible structure damage to the building and fear that the overhead crane in the building could collapse keeps the INL Fire Department from entering the building.

The CFA ECC planning manager obtains information on the burning chemicals and completes and faxes the consequence assessment form to the INL EOC.

The CFA EAM may request that an industrial hygienist report to the CFA ECC to assist with the response.

The CFA EAM determines a relocation area for the evacuated CFA-696 employees.

The INL Fire Department reports some employees are complaining of eye and throat irritations and directs eight of them to report to the CFA Medical Clinic.

The INL Fire Department reports all three vehicles in CFA-696 are fully involved and most of the eastside interior of CFA-696 is involved in the fire. There are additional pieces of equipment in CFA-696, including three buses, that the INL Fire Department anticipates will become involved in the fire.

INL Fleet Operations is relocating the buses from the CFA-696 parking lot to the CFA-685 parking lot.

Winds change from coming out of the south to coming out of the north, which requires the INL Fire Department to relocate the command post to the north side of CFA-696.

Due to the heavy black smoke that is now blowing toward the remainder of CFA, the CFA EAM may initiate a take shelter for CFA.

Field workers are directed to stay clear of CFA.

Security has roadblocks at Portland and Lincoln and Kansas and Main.

The CFA Medical Clinic requests that the INL Fire Department transport two employees to the Eastern Idaho Regional Medical Center for smoke inhalation problems. The INL Fire Alarm Center reports to the incident commander that Air Idaho Rescue is responding to the CFA Medical Clinic to transport the injured mechanic.

The CFA EAM consults with facility operations concerning water supply issues because the INL Fire Department has reported the fire could burn for several more hours.

Air Idaho Rescue arrives at the CFA Medical Clinic and transports the injured mechanic to University of Utah burn center for further treatment.

The CFA EAM will decide where to relocate the CFA-696 employees. The CFA EAM may consider closing the CFA area to all non-essential personnel.

The INL Fire Department reports that the 5-ton bridge crane in CFA-696 has collapsed, landing on the tanker truck and causing the remainder of the gasoline to be expelled and burn. The INL Fire Department is still performing suppression activities from the exterior of the building.

A recovery manager will be identified and report to the CFA ECC (simulated).

If all objectives are met, or the opportunity to perform or attempt to perform the objectives has been provided, or if the drill must be terminated due to time constrains with the realization that this fire would burn for many more hours, the drill director will/may terminate the drill. 